\title{
Regulated deficit irrigation reduces water use of almonds without affecting yield
}

\author{
by William L. Stewart, Allan E. Fulton, \\ William H. Krueger, Bruce D. Lampinen \\ and Ken A. Shackel
}

A plant-based regulated deficit irrigation (RDI) experiment in the northern Sacramento Valley determined that crop consumptive water use and irrigation could be reduced without significant detrimental effects on almond production. Tree stress was measured by recording midday stem water potential, a direct measure of tree water stress. With a water stress level of -14 to -18 bars during the hull-split period, average annual water savings were about 5 inches. Over 5 years, no significant yield reductions were observed, although average kernel weight was slightly lower. The results suggest that water savings can be achieved without affecting yield, even in soils with low water-holding capacity.

A Imonds are California's top agricultural export $-80 \%$ of those consumed worldwide are grown here. As water resources become increasingly scarce due to population growth, environmental needs and periodic drought, it will become more difficult both monetarily and politically to obtain sufficient water for crop irrigation. Drought tolerance in almonds has been documented in previous studies, but substantial irrigation is still required to maintain current production levels. Over the last 14 years there has been a steady increase in both bearing acres and yields - about 70 pounds per acre in almond yield improvement annnually (USDA 2010), indicating a steady improvement in cultural practices, among them, irrigation.

There is a pressing need to reliably maintain current almond production with less water. Surface-water

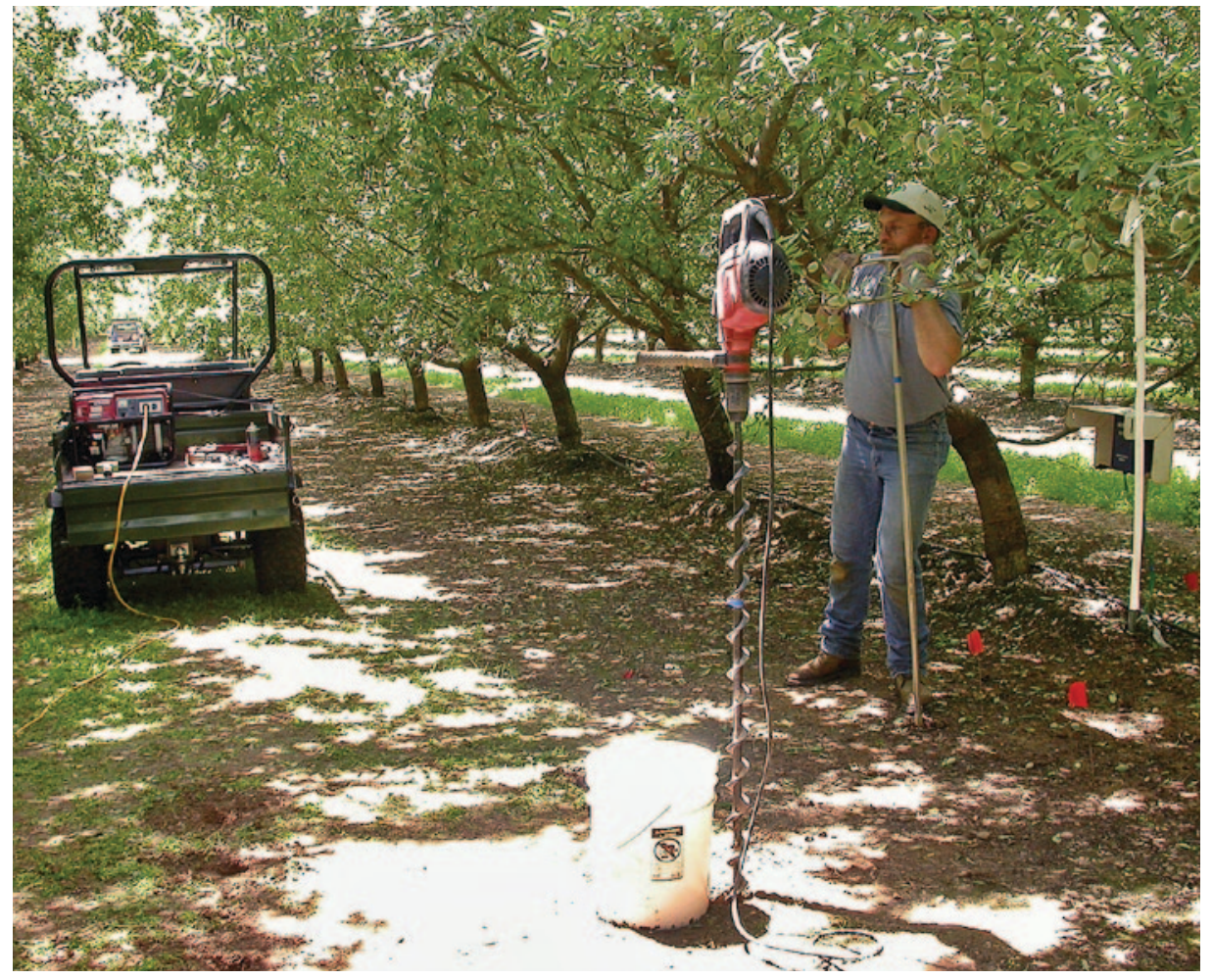

Microsprinklers are used in most almond orchards, allowing very precise measurements of how much water is being used by the trees. Above, Allan Fulton augured holes to install neutron-probe access tubes for monitoring stored soil moisture.

allotments for irrigation during drought are often significantly reduced because precedence is given to other uses (Fereres and Soriano 2006). Water reserves in California were low following the droughts of 2007, 2008 and 2009. In fact, spring 2008 was the driest on record (DWR 2009).

The current basis for estimating the irrigation need of a crop is to combine the water lost from the soil (evaporation) with the water lost through leaves (transpiration), into an overall loss, the crop evapotranspiration $\left(\mathrm{ET}_{\mathrm{c}}\right) \cdot \mathrm{ET}_{\mathrm{c}}$ is calculated by multiplying a weatherbased reference crop ET (in California, mowed, irrigated grass pasture or tall turfgrass species, " $\mathrm{ET}_{\mathrm{o}}$," are used), by a crop coefficient $(\mathrm{Kc})$, to give the final estimate $\left(\mathrm{ET}_{\mathrm{c}}=\mathrm{Kc} \times \mathrm{ET}_{\mathrm{o}}\right)$.

Research in the late 1980s and 1990s estimated the average seasonal $\mathrm{ET}_{\mathrm{c}}$ for almonds at 40 to 42 inches (102 to 107 centimeters), with estimated seasonal irrigation requirements of 36 to
38 inches (91 to 97 centimeters) under typical soil and rainfall conditions of the southern San Joaquin Valley (Goldhamer and Smith 1995). But later field research suggested that almond $\mathrm{ET}_{\mathrm{c}}$ may average from 48 to 54 inches (122 to 137 centimeters) (Sanden 2007). Reasons for the higher recent estimates probably reflect the many changes that have occurred in almond culture over the past two decades.

Almond orchards are now intensively managed with pressurized (e.g., microsprinkler) rather than surface (e.g., flood) irrigation systems, and crop water status can also be monitored directly using midday stem water potential (SWP). SWP is measured directly on leaves sampled in the orchard using a pressure chamber, and it indicates the level of physiological water stress that is being experienced by the trees at the time of sampling, much as blood pressure or temperature can be a measure of any physiological stress in humans 
(Shackel et al. 1997). Furthermore, nitrogen fertility management is more intensive than it was when the earlier research was conducted, and pruning practices have changed to manage canopy light differently, both producing more foliage and potentially higher $\mathrm{ET}_{\mathrm{c}}$. In fact, a higher $\mathrm{ET}_{\mathrm{c}}$ rate and higher yields may both be responses to moreintensive almond management.

The $\mathrm{ET}_{\mathrm{c}}$ method of irrigation scheduling aims to maintain the crop in a nonstressed condition by supplying enough water to satisfy $\mathrm{ET}_{\mathrm{c}}$. Alternative methods have been proposed that attempt to reduce unnecessary vegetative growth in orchard and vine crops in order to make water use more efficient; they include deficit irrigation, partial root-zone drying and regulated deficit irrigation (RDI) (Costa et al. 2007).

The objective of regulated deficit irrigation is typically to irrigate so that trees experience mild-to-moderate levels of water stress, in order to achieve an optimal horticultural balance between vegetative growth, which is very sensitive to stress, and fruit production, which is less sensitive (Chalmers et al. 1986). Previous studies in almonds and other crops have shown the beneficial effects of regulated deficit irrigation, including control of excessive vegetative growth, reduced hull rot and improved hull split in almonds (Goldhamer et al. 2006; Teviotdale et al. 2001; Shackel et al. 2003), increased fruit density in prunes and pears (Lampinen et al. 1995; Marsal et al. 2002) and reduced vegetative growth in peaches (Chalmers et al. 1986).

Previous studies of regulated deficit irrigation have created stress by applying a fraction of $\mathrm{ET}_{\mathrm{c}}$, but for this 5-year study we used a plant-based indicator of stress (SWP) and set a target level of mild-to-moderate stress during the hull-split period. We undertook this study to determine whether meaningful reductions in consumptive water use (i.e., the total of irrigation and soil moisture used by the orchard in a season) could be achieved with minimal impacts on orchard productivity.

\section{Testing deficit irrigation}

Our study took place in a microsprinkler-irrigated, 270-acre (109-hectare) almond orchard near
Orland in the northern Sacramento Valley, which was planted with 'Nonpareil' and 'Carmel' trees spaced at 12 feet by 24 feet ( 3.7 meters by 7.3 meters). The orchard was divided into five approximately equal blocks; two were planted in 1993 and three in 1999. From the first year of the experiment (2004), the canopy shaded area in midsummer (mid-June) at noon was greater than $50 \%$ in all blocks, so all blocks were considered to exhibit fully developed (mature) crop water requirements (DWR 1986). The five blocks were each subdivided into two sections to match the existing irrigation system design, with control and regulated deficit irrigation treatments assigned to the sections on alternating sides.

Two rows of 'Nonpareil' almond trees in the center of each section were designated as the experimental plots, with two trees from each block used as the monitoring trees for SWP measurements. The rows averaged approximately 69 trees per block, and monitoring trees were positioned approximately one-third and two-thirds of the way into each row (at approximate tree positions 23 and 46).

SWP values were initially taken on weekly field visits using a pressure chamber, and were collected biweekly during the hull-split period. Leaves, still on the tree, were covered with an aluminized Mylar bag for a minimum of 10 minutes prior to measurements (Fulton et al. 2001). Meters were installed on a single lateral line in each irrigation section to measure water applications.

In 2004 and 2005, block-specific recommendations for regulated deficit irrigation were communicated to the grower, who was responsible for dayto-day irrigation management. In 2005, the orchard exhibited defoliation due to Alternaria leaf spot, and the grower was reluctant to withhold water from the large regulated deficit irrigation plots.

In 2006, a separate irrigation system that could be monitored and controlled via a satellite-linked Internet service (Automata, www.automata-inc.com) was installed for the experimental 'Nonpareil' row and the two adjacent

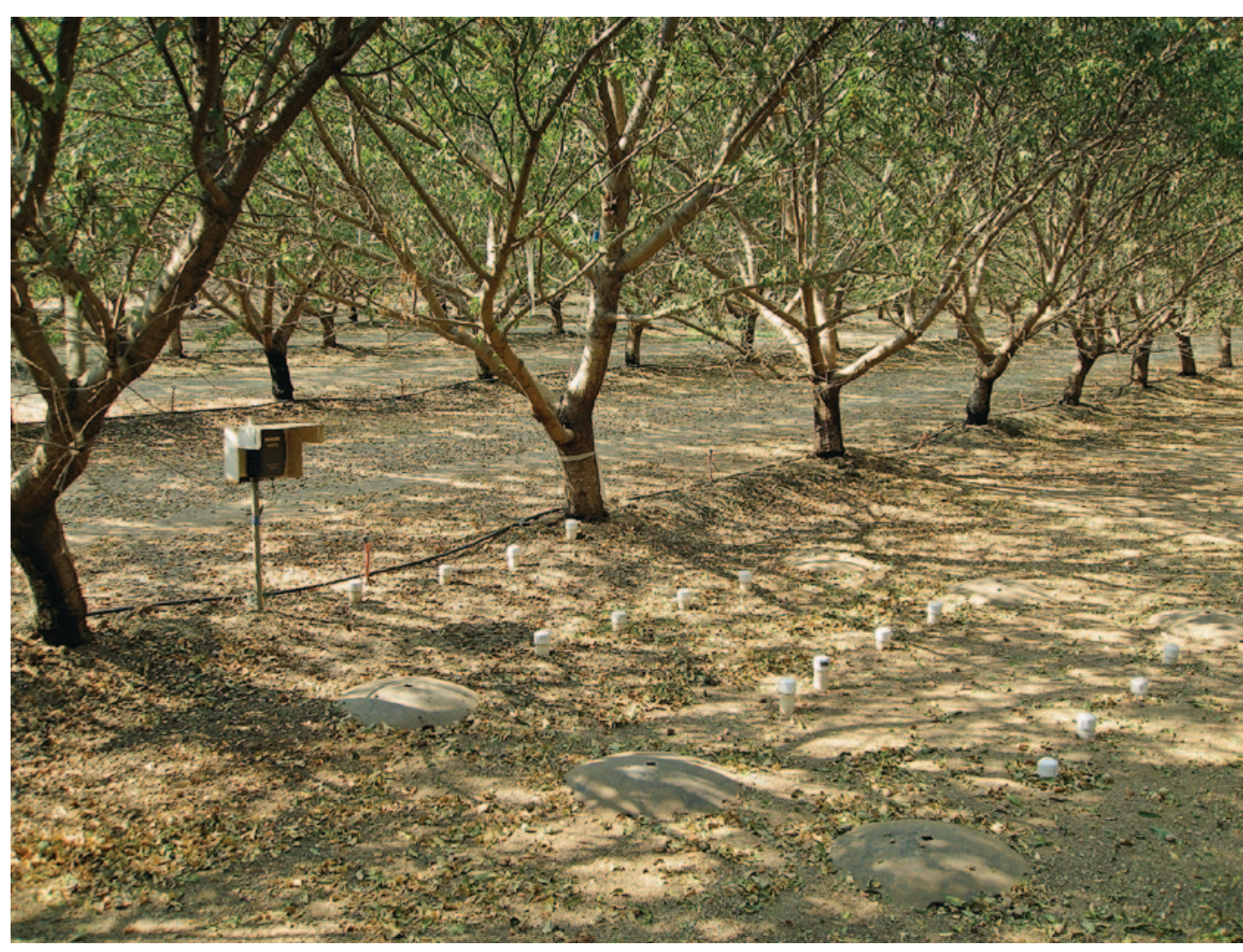

Grids of neutron-probe access tubes allowed the researchers to take soil moisture readings at different depths. They found a shallow water table that receded throughout the growing season, especially during two drought years. 
pollenizer rows in each regulated deficit irrigation block. The system included flow meters to monitor irrigation and a weather station to measure rainfall, air temperature, humidity and other parameters. Picovale Services ( $w w w$. picovale.com) developed and supported a program to remotely control the on and off times for each block independently via the Internet. Reference $\mathrm{ET}_{\mathrm{c}}$ $\left(\mathrm{ET}_{\mathrm{o}}\right)$ from a nearby CIMIS (California Irrigation Management Information System) station (\#61 at Orland; discontinued in 2010) was used to estimate crop water demand and was combined with published crop coefficients for mature almonds (DWR 1986) and adjusted for the full-bloom dates (Mar. 5, 2004;

Feb. 20, 2005; Mar. 1, 2006; Feb. 21, 2007; and Feb. 29, 2008).

\section{Utilizing stem water potential}

Midday SWP and water meter data until the hull-split period. Visual surveys were made weekly starting in mid-June to anticipate the beginning of hull split. Irrigation was reduced once in blank nuts, generally about a week before the onset of hull split in normal (filled) nuts. Before and following the were collected weekly from early April the onset of hull split was observed

hull-split period, the water amounts applied to the regulated deficit irrigation and grower control (full irrigation) treatments were equivalent. During the hull-split period, SWP was measured twice weekly and irrigation was adjusted to achieve a target mild-tomoderate stress level of -14 to -18 bars $(-1.4$ to -1.8 megapascals [MPa]) in each block.

By the last year of the study (2008), block-specific irrigation was not necessary because the target SWP could be achieved using about the same level of deficit irrigation in all the treatment blocks. The target levels of midday SWP employed in this field trial were set to achieve mild-to-moderate water stress during the regulated deficit irrigation period. For almonds, Shackel (2007) reported about a 50\% reduction in midsummer stomatal conductance with SWP values of -14 to -18 bars $(-1.4$ to $-1.8 \mathrm{MPa})$ compared with a nonstressed (no soil water limitation) SWP above -10 bars $(-1.0 \mathrm{MPa})$ (Shackel 2007; Shackel et al. 1997). Irrigation was returned to normal once visual surveys indicated $90 \%$ hull split in each block.

The grower commercially harvested entire rows, and a weighing trailer was used to determine gross harvest weight

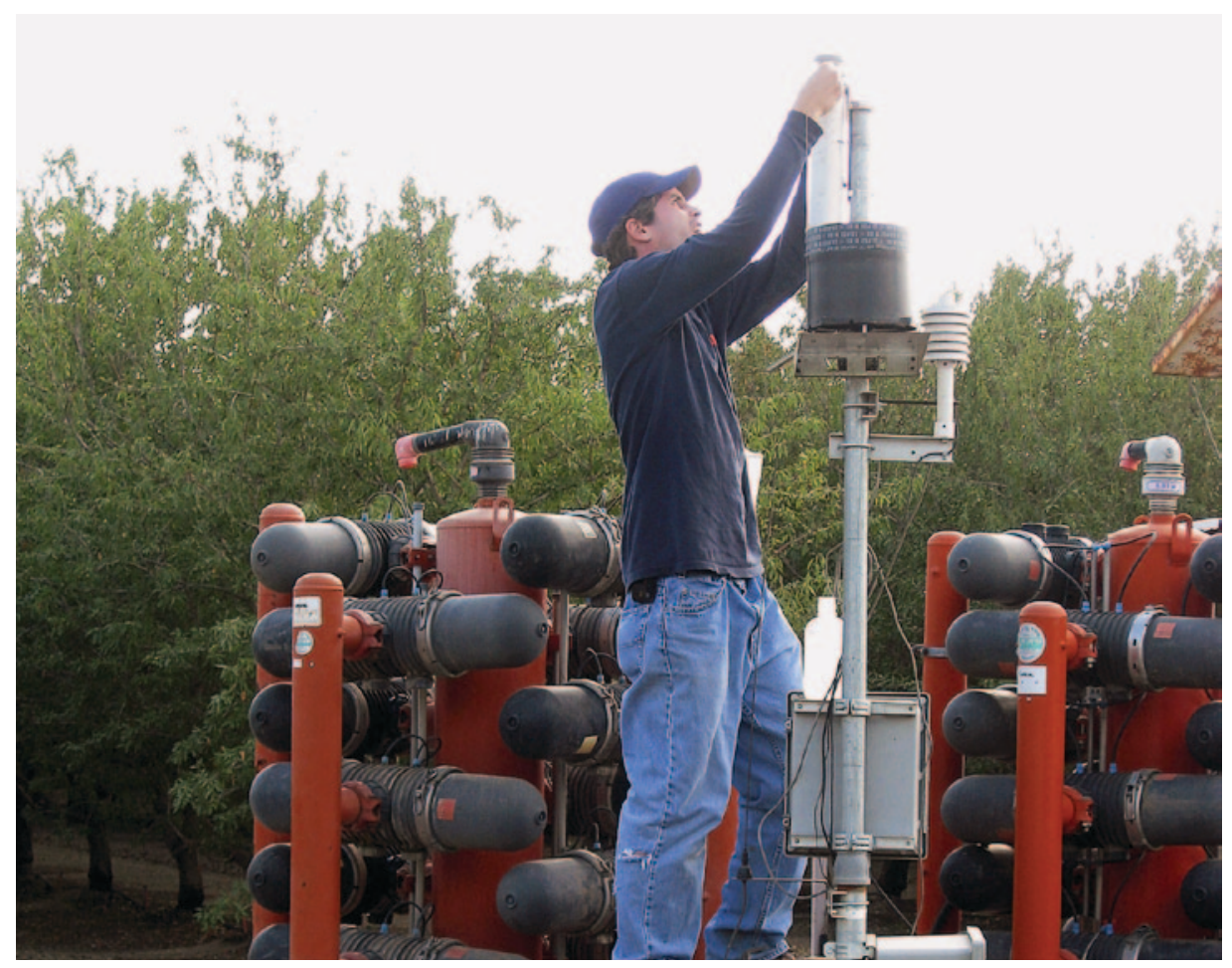

William Stewart checked the evapotranspiration gauge on the almond orchard's weather station. These measurements are used to calculate the amount of water lost by the crop. in the field. We collected a 4-pound (1.8-kilogram) subsample from each of the blocks and used them to convert harvest weights into nutmeat yields.

In this field trial, regulated deficit irrigation was limited to the hull-split phase of almond growth and development. $\mathrm{ET}_{\mathrm{c}}$ is typically highest during midsummer, so the opportunity is greatest at this time to impose crop stress in order to achieve significant irrigation reductions. In addition, Teviotdale et al. (2001) reported that both hull split and nut harvestability are improved and hull rot is reduced when regulated deficit irrigation is imposed during the hull-split period. Other stages of almond growth and development have shown greater susceptibility to negative impacts on tree growth and nut production (Goldhamer et al. 2006). Crop stress is also difficult to impose from leaf-out through midMay due to rainfall, lower $\mathrm{ET}_{\mathrm{c}}$ rates and generally sufficient soil moisture.

\section{Measuring soil parameters}

Soil moisture. We installed neutronprobe access tubes to measure the change in stored soil moisture from early spring to late summer, in order to quantify the contribution of soil water to the crop's water needs (in addition to applied irrigation water). We installed two grids of 16 tubes (schedule 40 PVC) in a single block, each in the southwest quadrant of a single monitoring tree for both the regulated deficit irrigation and control treatments. The tubes were arranged in 4-by-4 grids with overall dimensions of 6 feet by 12 feet $(1.9$ meters by 3.7 meters). The grid spacing was measured from the center of the tube, with 2-foot (0.6-meter) spacing in the north-south direction and 4-foot (1.2-meters) spacing in the east-west direction.

We tried to install the tubes to an overall depth of 60 inches (152 centimeters) and measure volumetric soil water content at 1-foot intervals, at depths of $8,18,30,42$ and 54 inches $(20,46,76,107$ and 137 centimeters). However, due to the widespread variability in soils including areas with significant gravel content, soil stratification and a shallow, temporarily perched water table (particularly in March and April) - we achieved a depth of 54 inches (137 
centimeters) for only 22 of the 32 tubes The remaining tubes were installed to a depth of 42 inches (107 centimeters). Soil moisture readings were taken two or three times per season, typically around full bloom, in late summer and postharvest.

The shallow water table receded during the course of each growing season, especially during the drought years of 2007 and 2008; it did not appear to influence orchard water status significantly during our study. If capillary flow of water from the shallow water table had contributed significantly to crop consumptive use, midday SWP would not have responded to the withholding of irrigation water during hull split. In addition, the gravel content and hardpan appeared to be barriers to deeper root development, so the roots may not have reached the soil water.

Soil type. Soil types were variable throughout the orchard, but the majority of acreage consisted of three types: (1) Cortina very gravelly sandy loam, (2) Hillgate loam and (3) Redding gravelly loam (USDA 2009). These soils are described by a USDA land capability rating of 3 or 4 , which generally groups soil types based on restrictions for field crops. The Redding soil typically has a restrictive layer at 20 to 40 inches (51 to 102 centimeters), and the other soils extend to below 80 inches (203 centimeters). Based on a nominal 60-inch (152-centimeter) soil profile, all have low available water — approximately 3.5 inches (9 centimeters) for the Cortina and Redding soils and 8 inches (20 centimeters) for the Hillgate soil (USDA 2009). The two grids of neutron-probe access tubes were positioned in either a Cortina or Redding soil type.

Groundcover. Groundcover varied between mowed resident vegetation in spring and winter, and bare ground in summer. Vegetation around the neutron-probe access tubes, where a mower could not be used, was controlled with herbicides each spring to match the surrounding vegetation.

\section{Reductions in water use}

Water savings. An average water balance summary for 5 years of this study showed overall savings of 4.8 inches (12.2 centimeters) of applied water in the regulated deficit irrigation regime

TABLE 1. Average estimate of consumptive water use in control and regulated deficit irrigation (RDI) treatments, 2005-2008*

\begin{tabular}{|c|c|c|c|c|c|}
\hline Treatment & $\begin{array}{c}\text { Seasonal applied } \\
\text { water }\end{array}$ & $\begin{array}{c}\text { Seasonal } \\
\text { precipitation }\end{array}$ & $\begin{array}{c}\text { Contribution } \\
\text { from soil storage }\end{array}$ & $\begin{array}{l}\text { Consumptive } \\
\text { water use }\end{array}$ & Modeled $\mathrm{ET}_{\mathrm{C}}$ \\
\hline \multicolumn{6}{|c|}{ 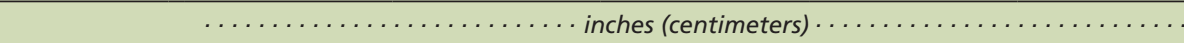 } \\
\hline Control & $39.3(99.8)$ & $4.1(10.4)$ & $5.0(12.7)$ & $48.4(122.9)$ & $44.4(112.8)$ \\
\hline RDI & $34.5(87.6)$ & $4.1(10.4)$ & $4.5(11.4)$ & $43.1(109.5)$ & $44.4(112.8)$ \\
\hline
\end{tabular}

All in-season precipitation was assumed to be effective, and modeled ETc values were based on DWR 1986.

(table 1). The neutron-probe readings showed an average seasonal contribution of approximately 5.0 inches (12.7 centimeters) of stored water in the control and 4.5 inches (11.4 centimeters) in the regulated deficit irrigation treatment, amounting to about $11 \%$ of overall consumptive water use. All inseason precipitation was assumed to be an effective contribution. When the savings in applied water were combined with the contribution from soil storage, the regulated deficit irrigation regime resulted in a total average annual consumptive-water-use savings of 5.3 inches (13.5 centimeters) over the 5-year period, and yearly savings ranged from $10 \%$ to $15 \%$, or 5.2 to 6.1 inches (13.2 to 15.5 centimeters) (table 2).

Yield increases. Yields increased in both treatments during the 5-year study, with no clear trend of any reduction due to regulated deficit irrigation (fig. 1). The orchard's increasing yields can be attributed to its relatively young age (9 to 14 years) and continuing canopy growth. Canopy growth is typically very sensitive to deficit irrigation, so it is noteworthy that plant-based regulated deficit irrigation did not have a negative impact on yields over time, presumably because the deficit period was after the main period of vegetative growth.

Nutmeat production. Even though regulated deficit irrigation consistently reduced applied water compared to the control (tables 1 and 2), variation was high enough to prevent the regulated deficit irrigation from having a statistically significant effect on the gallons of irrigation water used to produce 1 pound of nutmeat (table 3). Statistical analysis (ANOVA, not shown) for yield and irrigation water used per pound of nutmeat showed that both block and year effects were highly to very highly significant, presumably as a result of

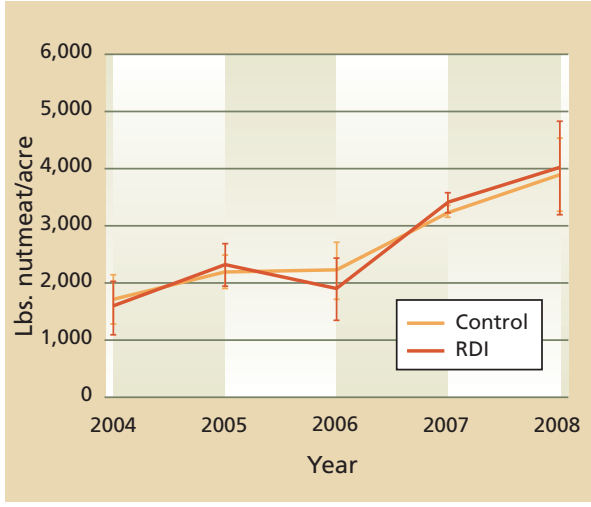

Fig. 1. Annual pattern of nutmeat yield, 20042008. Error bars are \pm 2 SE.

\begin{tabular}{|c|c|c|c|}
\hline \multicolumn{4}{|c|}{$\begin{array}{l}\text { TABLE 2. Consumptive water use and overall } \\
\text { percentage savings, 2005-2008 }\end{array}$} \\
\hline \multirow[t]{2}{*}{ Year } & Treatment & Consumptive use & Savings \\
\hline & & inches $(\mathrm{cm})$ & $\%$ \\
\hline \multirow[t]{2}{*}{2005} & $\mathrm{RDI}^{*}$ & 34.6 (87.9) & 15 \\
\hline & Control & $40.2(102.1)$ & \\
\hline \multirow[t]{2}{*}{2006} & RDI & $36.0(91.4)$ & 13 \\
\hline & Control & 41.6 (105.7) & \\
\hline \multirow[t]{2}{*}{2007} & RDI & $47.1(119.6)$ & 10 \\
\hline & Control & $52.3(132.8)$ & \\
\hline \multirow[t]{2}{*}{2008} & RDI & $42.6(108.2)$ & 13 \\
\hline & Control & $48.7(123.7)$ & \\
\hline
\end{tabular}

fixed block-to-block variability in the soils as well as the combined effects of year-to-year variation in weather conditions, especially during flowering, and the increasing yields over time.

Nut quality. Over 5 years, we found only two statistically significant effects on nut quality under regulated deficit irrigation: a decrease in kernel weight and an increase in the percentage of severe shrivel. Average nut size was 1.18 grams $(\mathrm{SE} \pm 0.12)$ in the regulated deficit irrigation treatment and 1.21 grams $(\mathrm{SE} \pm 0.12)$ in the control $(P>0.02)$. There was severe shrivel in $13.0 \%$ (SE \pm 9.3 ) of nuts sampled from the regulated deficit irrigation 
treatment and 9.0\% (SE \pm 5.3) from the control $(P>0.05)$.

The nonsignificant effects measured were nut moisture; percentages of sealed sutures, doubled kernels, twin kernels, blanks, broken kernels, creases, slight shrivels, rupture calluses, gums, molds and stains; and damage by navel orangeworm, ants and peach twig borer. For most of the quality factors measured, the effect of year, but not block, was also highly to very highly significant (table 3; ANOVA not shown).

Hull split. Previous research showed that regulated deficit irrigation can increase the rate of hull splitting (Teviotdale et al. 2001), but in this study we observed no measurable differences in the duration or extent of hull split between treatments in any year (data not shown).

Plant water deficit. The SWP values in both treatments were approximately equivalent before and after the regulated deficit irrigation period, but were much lower (trees were more stressed) compared to the control during the hull-split period (fig. 2). This indicates that a well-defined and reproducible plant water deficit was achieved during hull split in the regulated deficit irrigation treatment.

For much of the growing season (14 to 32 weeks from full bloom),
TABLE 3. Yield and irrigation water used per pound nutmeat for control and regulated deficit irrigation (RDI), and probability ( $P$ value) for treatment effect, 2004-2008*

\begin{tabular}{lcc}
\hline Treatment & Yield & Irrigation used \\
\hline & $\begin{array}{c}\text { Ibs. nutmeat } \\
\text { per acre }\end{array}$ & $\begin{array}{c}\text { gallons per } / b . \\
\text { nutmeat }\end{array}$ \\
Control & $2,640 \pm 920$ & $458 \pm 193$ \\
RDI & $2,640 \pm 1090$ & $428 \pm 213$ \\
$P$ value & 0.99 NS & 0.22 NS \\
* Based on three-way ANOVA (year, block and treatment).
\end{tabular}

particularly around harvest time (25 to 28 weeks from full bloom), SWP in the control was also lower than expected for almond trees with nonlimited water (the nonstressed baseline) (Shackel et al. 1997). This effect may be attributable to a small deficit in water applied by the grower as a result of cutbacks in water availability.

\section{Deficit irrigation in practice}

The orchard site used in this study presented several difficulties in implementing regulated deficit irrigation as a management technique, in particular the site's relatively shallow and spatially variable soil with low water-holding capacity, and two comparatively dry years (2007 and 2008). Both of these factors might lead to an excessive and potentially damaging level of stress when irrigation is reduced, particularly just prior to harvest in almonds, when irrigation must be discontinued to allow for mechanized harvesting. However, using a simple, plant-based approach, consistent water savings of more than 5 inches (12.7 centimeters) or about 13\% of applied water were achieved with no detectable effects on short- or mediumterm orchard productivity. When regulated deficit irrigation was compared to the control, there was an annual water savings of 0.4 acre-foot (1.2 megaliters per hectare).

Although no significant reductions in overall yield or gallons of irrigation water used per pound of nutmeat were observed in our study, significant reductions in yield have been documented in previous deficit experiments with almonds. The negative effects in those studies were not extreme, and the yield reductions were generally associated more strongly with water deficits imposed during postharvest than during hull split. In a 4-year study by Girona et al. (2005), a statistically significant $(20 \%)$ reduction in overall yield was associated with a $40 \%$ reduction in water application and a nonsignificant $(3 \%)$ reduction in kernel dry mass. In our study, the overall treatment difference in kernel dry mass of $2.5 \%$ was

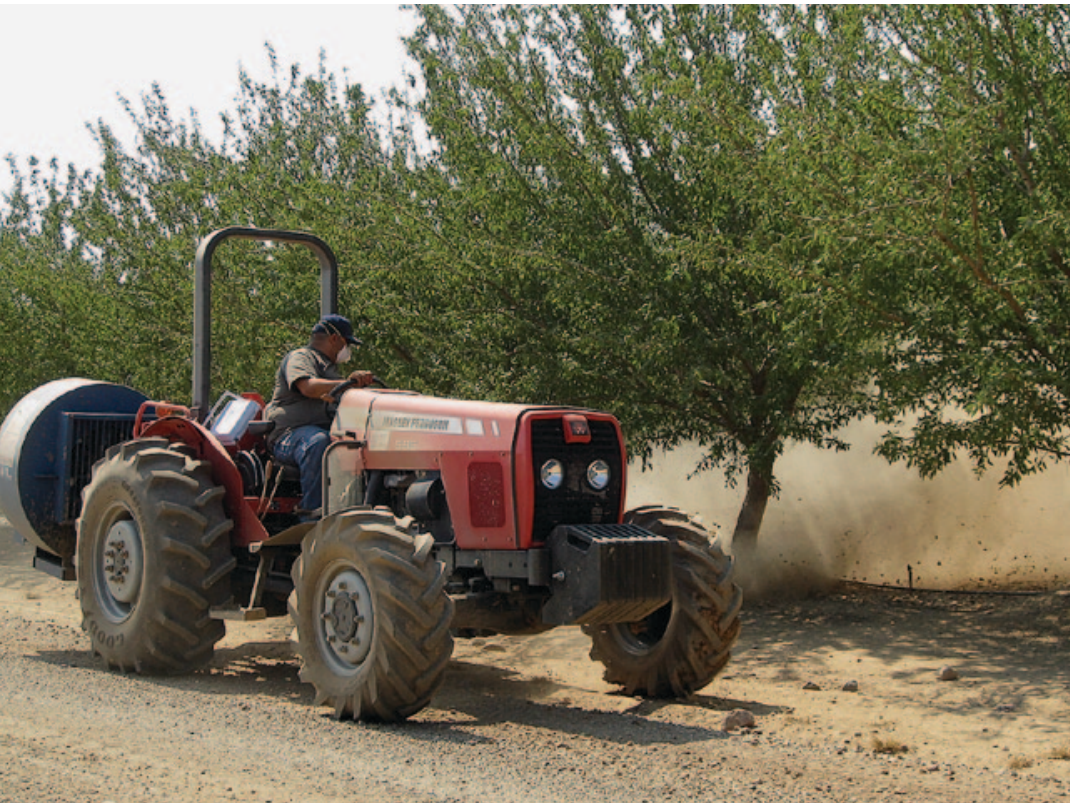

The study did not measure any almond yield reductions attributable to regulated deficit irrigation. Yields increased in both treatments due to the orchard's young age and ongoing canopy growth. Above, almonds are swept into windrows.

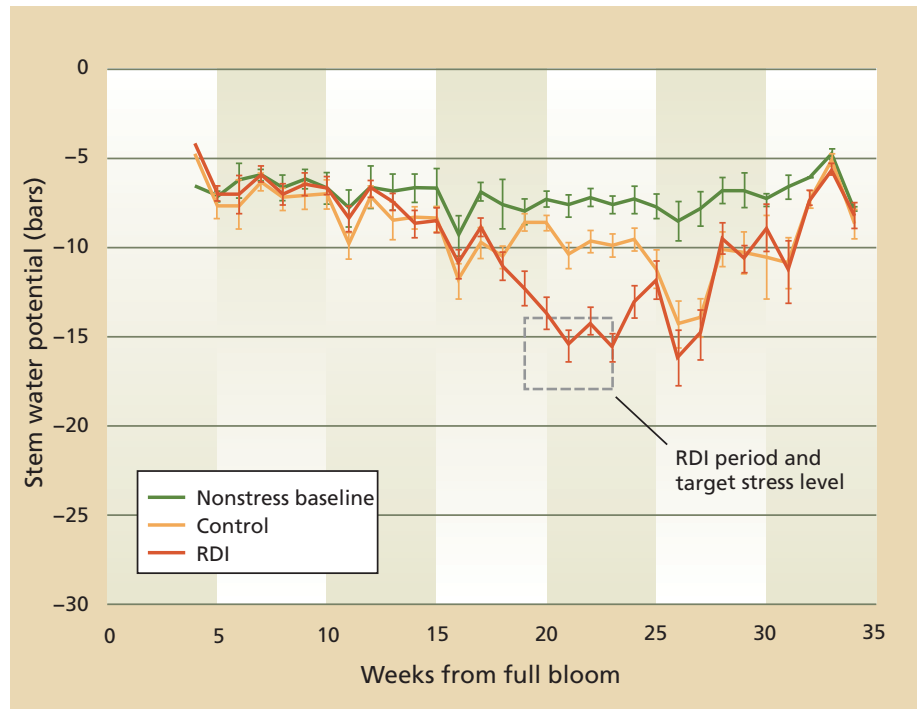

Fig. 2. Seasonal average pattern of stem water potential (SWP) values for control and regulated deficit irrigation (RDI) treatments, with upper and lower limits of target water stress and average duration of RDI regime, and seasonal average expected SWP values for nonstressed almond trees, 2004-2008. Nonstressed baseline values (Shackel et al. 1997) were calculated using CIMIS data for atmospheric vapor pressure deficit; 2005 data was excluded from analysis. 
